\title{
Beauty of Zombies and the Field of Plastic Surgeries
}

\section{Rimpa Mondal}

\begin{abstract}
The opposing concepts of health and illness are driving the medico-social research community and also affecting the image people construct of themselves and others since ages. The binary of beauty and monstrosity also runs parallel to the former pair. The advances and virulence of cosmetic surgeries globally have created new normative standards to be achieved. Zombie bodies are depicted as cinematic metaphors of illness and monstrosity and as pawns working under the authoritative gaze of the medico-political section that has the advantage of information-power-knowledge. In this paper, these defunct bodies have been differently repositioned here and will be seen as consenting human subjects with a desire to achieve a bodily ideal which has been made realistic by medico-surgical advances and their politico-social redefinition. The narrative tragedy lies in their failure to achieve the desired result post-surgery and their physical-material reconstruction as 'incomplete' versions of their previous selves. This idea of medical science promising more than what it can deliver has been argued in the present paper, alongside Body Dysmorphic Disorder (BDD). The paper discusses the equivalence of this virulently popular desire for surgical modification to the cinematic process of zombification. The zombification process which from its supernatural origin turned to medically-aided transformation has been studied here. This extended correlation has been read as one of the many types of viral behavioural traits prevalent in society. The idea for the present paper came from a personal interpretation of the South Korean web series Kingdom (2019) released on Netflix in two seasons.
\end{abstract}

Keywords: Viral Behaviour, Zombie, Cosmetic Surgery, Normativity, Monstrous Body.

\section{Introduction}

The South Korean Netflix web series Kingdom (Lee ,2019) and its 2020 sequel Kingdom 2 came with the well-explored cinematic narrative of a zombie pandemic. The series narrates the account of a zombie incursion in the medieval Joseon era ruling over the Korean peninsula which coincides with the Enlightenment era of the West. The zombies of the Kingdom series are a medical experimentation on the sick people of Sumang village. The villagers are transformed so that they can help to save the Joseon kingdom during a military onslaught by the outnumbering Japanese soldiers during the Imjin war (1592-98).

The medieval setting and the military necessity put a tragic heroic mantle over the zombies. Simultaneously, it represents these 'bodies' as results of an unethical medical experimentation because it was conducted on unaware and non-notified subjects. It highlights the unquestioned power of the one who ordered the experiment, Lord Cho Hak-ju. The narrative purpose gets fulfilled in painting Lord Cho as an evil intentioned villain who allows the unethical practice of medical zombification. His power is in that the medieval Joseon society led by the Crown Prince Chang is helpless to control its impact or stop it ${ }^{\mathrm{i}}$. Lord Cho holds a central position in their monarchic Joseon society. But Joseon must be read as a 
Deleuzian society of control forming out of a Foucauldian society of discipline.

The immanence of social control in the form of 'biopolitics' plays an important role in the discussion of zombies in this paper. There is a new paradigm of power which is diffuse and immanent in a society of control. The social inclusion and integration of bodies is possible only when the embodied interactions gain permission and acceptance. The paradigms for such an acceptance in these societies remain enclosed and exclusive, even when they are 'public.' It is also a characteristic feature of modern societies, and that is why the Joseon setting and zombie figure are of relevance even now. Hospitals or medical institutions are also among the major disciplinary institutions, so their episteme of powerknowledge prominently impacts the paradigm for the inclusion of bodies as 'normal' or not. Lord Cho, while convincing Lord Ahn Hyeon ${ }^{\mathrm{ii}}$, says that the sick people on being zombified can aid the Joseon nation-state in their transformed state and so, they can be of use at least in their monstrosity. The statement plays a great role in making the desisting Lord Ahn accept the medical administration of the process and also in establishing the authority of the medical institutions over the definition of what 'health' and 'normality' is.

The use of living bodies is ethically fraught with questions and so in itself becomes a topic of discussion; but in this essay, this very use of living bodies for experimental purposes will be looked at with the assumption and the perspective of seeing them as consenting subjects. What makes it important for discussion is the idea that in Kingdom, Lord Ahn was successfully convinced by Lord Cho of the practical uses of such an experimentation, which was to reverse the result of the battle against the Japanese forces. Even medical personnel like the Royal Physician Lee Seung-hui could be commanded to perform these surgeries and keep records of it dutifully. It was already understood to be a successful experiment, to the extent that he eventually dies while trying to find a way to establish the validity and success of the procedure. So, the possibility must not be ignored that the sick people of Sumang village after their capture could have been similarly convinced of a positive outcome of this procedure, wherein they could have been promised of regaining their health and becoming so healthy that they could take active part in the battle as the regular, healthy and able-bodied soldiers.

The above presumption is made because the medical profession with its modern advances does not just promise health and recuperation from illnesses. It also offers corrections of such aspects of the body which seem unfavourable, unnecessary and unnatural. Therefore, there is a medical solution whenever a given body is seen as deviating from the ideal or normative bodily requisite in some way. Though this may not be to the extent of being called 'monstrous' by itself, yet people undergoing such surgeries oftentimes think otherwise. It is definitely considered as not 'appealing.' People, going for surgeries like rhinoplasty, breast and buttock enhancement surgeries, or liposuction, choose to have their aesthetic 'deficiency' removed or improved for the best. This idea of an anthropocentric standard to which all bodies must cohere has been central to the disciplinary birth of medical science since its conception. It is more apt in the case of the field of plastic (aesthetic and reconstructive) surgery.

\section{Modified Bodies}

Health and beauty are mostly seen as two sides of the same coin. The beautiful one is necessarily the healthy one, and vice versa. But beauty standards have shifted over time and in all cultures across the world. In tandem, the standards which demarcate 'normalcy' in humans also underwent many fluctuations. The notoriously remarkable instances are of Ohagaru (teeth-blackening) among Japanese women, foot-binding in Chinese women, and corset-bindings for waists and chests among Victorian women ${ }^{\text {iii }}$. They were seen as the markers of beauty and thus, also of health. In some tribes of Africa, a heavy body weight which is supposed to be a sign of good health in women and, thus, also the sign of beauty. The ideal weight is achieved through the oppressive practice of leblouh or (Fr.) gavage, 
meaning force-feeding. The modern era has provided individuals with more liberty in terms of determination of individuality, sexual orientation and gender identification. This has also increased the reasons for which people go for surgical body contouring and modification to adhere to new body standards. People can now opt to restructure their bodies if it feels uncomfortable or incomplete.

The above contention suggests that the body also determines the completeness and wholeness of an individual's self-identity. With the idea of an incomplete body comes the idea of incompleteness of a person. So, the Cartesian value of mind-body dualism largely falls into being biased and misconstrued. Though Descartes said that the amputation of an arm or a leg cannot disrupt his idea of himself, the increase in cosmetic surgeries and reconstructive surgeries make it seem otherwise. The body is an external attribute (a possessed object) of the mind according to Descartes. But it cannot be considered 'normal' if the leg or arm is cut off, especially because prosthetic limbs can achieve that whole which earlier someone could only wish for. A complete personhood is only possible when the body is 'complete', along with the mind. That is why the disabled and sick bodies were for many years not accepted as 'normal.' Same was the paradigm for racially different bodies. These bodies were considered to be incomplete and, therefore, monstrous.

\subsection{Normal or Monstrous?}

It is only in an embodied interaction (in a Deleuzian society of control) where the ideas of normality and monstrosity are approved or made redundant. The only condition of normality is that a body must be difficult to be identified separately from the group; a normal body has to be invisible. Otherwise, it would be a Bakhtinian spectacle, an object on display. It would be under constant scrutiny, and so, be an excluded 'other.' Visibility, in this context, acknowledges the active nature of perception which Foucault termed 'affordance.' In a study on the increase in cosmetic surgeries among Canadian men, Michael Atkinson states that for many of the respondents, the medical intervention was intended "to allow the individual to fade into a crowd as a "regular guy" (Atkinson, 2008, p.77). This 'un-remark-worthy' invisibility which associates the body with normality is not readily available to two groups: the sick and the disabled people. Sick and dis-abled people in the corporeal visibility cannot hide their deviation from the bodily ideal in a society that is constantly evaluating every 'body.'

Therefore, the treatment of sickness or disability is based on medical science's promise to look for 'perceived' symptoms and remove or supplant them. In the idea of supplanting, there has to be an increased efficiency and performance too. That is the reason why plastic surgery has gained ground and favour among the population. The American Society of Plastic Surgery (ASPS) in a tagline on its website's homepage states that cosmetic surgeries can now help people to "improve abilities, function and quality of life" in cases of physical damage due to trauma, disease, congenital defects or to reach aesthetic goals. It also as its own limitation considering its availability (considering income, gender and regional accessibility), but we do not focus on them in this paper. Still, we can broadly claim that the field of plastic surgery has made a 're-birth into society' possible for people discontented with their physiological-social presence and presentation.

\subsection{Promises and Punches}

Since the advent of the specialised sub-field of cosmetic surgery, 'beauty' has become an external attribute which can be bought and made 'real' in an operating room. The current health-beauty standards suppose 'normal' body to be something that can be artificially attained. So, surgeries provide a means to rectify the non-standard and non-aesthetic corporeality, aided with its medical advances (invasive and non-invasive surgery). In an eerie 
historical mention, the Nazi Final Solution also originated out of a kind of aesthetic erasure of what was obscene and unsettling (Ozick, 1984; Bauman, 1995). This is somewhat akin to the discursive foundation of plastic surgery which offers a path to remove physical aberrations from visibility by operating upon them.

People undergoing such modifications have an idea about their body which is constructed in a socio-medical discourse. This discourse defines normality as a harmonious collective presence. Those who do not feel that their bodies are assimilating rightly into the social harmony, they create a dysmorphic idea of themselves. It may often be a psychological condition in itself. Body Dysmorphic Disorder (BDD) is already one of them, along with anorexia and bulimia. Low self-esteem and agoraphobia may also develop due to such an insecurity about physicality. Furthermore, the socially-valued ideas of completeness and normality of a body is not just a problematic issue for the sick and disabled people. Some 'able-bodied' individuals, who for various reasons have a dysmorphic self-identity, also face problems in assimilating into a crowd because of the imbibed idea of normality. With an immanent societal control over the idea of normality and an equally incisive evaluation that bodies undergo at all times and all places, the health of the body no more remains an intimate issue but one that is public and must be visible too.

Healthy and normal bodies need to look so, and that is why they must be 'beautiful.' Beauty is to be understood in the sense of a celebrity-emulated and aesthetically symmetrical bodily constitution. The great influence of celebrity bodily re-presentation on the idea of 'beautiful' body is an important aspect, which has been remarked also by Anthony Elliott in his essay (Elliott, 2010). The problem is that all these issues of normality, beauty and health have been unrealistically overlapped, but these standards are still being pursued unsuccessfully by the society. Arthur Frank in his essay contends that illness is now a state that is coexisting with health. So, people's bodies have become a no-man's land, never properly healthy or completely sick (Frank, 2005). Everyone lives in a constant state of illness. It is in itself a statement on the modern paradigm of 'health.' Now, 'health' is determined by three criteria: it is not whether one is absolutely free of any disease. Rather, how well one copes with the diseases persisting in his body, how one has superimposed the disease with a camouflaging element and also how one can make use of latest biomedical technology to aid the camouflaging or altogether remove an undesired element or feature from the body.

The medical scientific intervention through cosmetic surgery tries to bring into visible reality that aspect of 'self' which was not or could not be rendered dominant in the original genetic constitution. This raises the ethical questions of how much of a bio-physical-medical transformation can be accepted as normal or normalising, and when such interruptions transform the body into something which becomes monstrous. Discussing these contentions must be included in studies by plastic surgeons, psychiatrists and psychologists, alike. Medical surgeries in the country of South Korea, from where Kingdom (2019) originates, is known for its cosmetic surgeries easily and cheaply available to all those consenting. Even in other countries, cosmetology is often seen as the easy way out to become one of the 'normal', that is to be just as the others. There are 'deformities' that can be removed or made better like surgeries for cleft lips, noses, eyelids, unwanted fat which are the most commonly done. For such cases, one can choose the available surgical modifications with its torture and pain over the imminent social ostracization and bullying.

\section{A Zombifying Process}

The possibility of getting surgically rectified physiques has brought about a radical increase in their number globally. The 2019 report released by ASPS shows an increase of about $1 \%$ and $2 \%$ in the numbers of reconstructive and minimally-invasive cosmetic surgeries respectively, in the USA alone. But it is a huge $169 \%$ increase compared to the data of year 
2000, which mostly inclines towards aesthetic body enhancement (ASPS,2019). In the ISAPS global statistics of 2019, South Korea is fifth among countries with the highest number of plastic surgeons and India is among the top 10 countries that performed the highest number of surgical procedures. There was also a $7.4 \%$ increase in the total surgical and non-surgical procedures in the world, according to the press report (ISAPS, 2019).

These percentage changes in the 'virulence' of (aesthetic) plastic surgeries reveal the viral ideological change regarding the concept of bodily 'wholeness.' The body is now understood in collaboration with the medical aides attached to it, just as earlier each body was known with the accessories attached with it. Like piercings, headgear, tattoos and even wounds become part of the body, and become integral to the identity of a person. In the same way, spectacles, hearing aids, artificial cardiac pacemakers and prosthetic limbs have become 'parts' of the body. The idea of using prosthetics for being 'pro-aesthetic' or being beautiful (that is, natural) to look at in public has also infused within the idea of undergoing a cosmetic surgery.

These medical modifications try to help people achieve their desire to be beautiful and maintain a social standard. People, who feel that their lack of social success and evaluation is due to their non-assimilating physical bodies, choose to undergo bodily modification to attain the necessary motivation and sense of achievement. The problem is only when people undergo radical (and sometimes life-threatening) modifications compulsively. It only pushes them more into the realm of the 'unnatural.' There has emerged a psychological disease among former in-patients of the departments of plastic surgery. Plastic surgery addiction is a behavioural compulsion to change their appearance with multiple surgeries. In such a dangerous addiction, the effect of such processes on the mental health of people is as damaging as due to BDD. Both the addiction to perfection and the respite found in continuous surgeries are here paralleled to the cinematic idea of zombification. It can specially be made pertinent considering cases iv where people have been ridiculed even after undergoing the procedure and where it has killed the patients.

Zombification, therefore, must be seen not just as a psychological, supernatural or cinematic process that has no relation to the everyday. Rather the association drawn with cosmetology on the whole is also of prime significance. Losing control over the conscious self for reasons like voodoo, biological or technological interference is possible when exerted by others. But such a loss of agency is also included in a psychological self-torture due to maladaptation to society and to one's body. The high hopes from surgery must not reach levels of becoming a dangerous Cinderella complex ${ }^{\mathrm{v}}$ of its own kind (because it would be gender-neutral). Surgery cannot possibly be the 'knight-in-shining-armour' for people who can save them by completely transforming them. There are side-effects of surgeries (often devastating and non-reversible) which medical surgeons must make patients aware of.

Medically-assisted metamorphosis does not always pave the way for the 'amazing' to be born. Sometimes even the abhorred aspect can surface instead. The transformation of the weak and ailing Steve Rogers to the strong and robust Captain America ${ }^{\mathrm{vi}}$ included an enhancement of the genetic component into its best version. It can also be identified as a kind of zombification. But there is a need to realise that there is every possibility that the result of such a transformation may be a primordial and 'disfigured' Red Skull, instead. Similarly, the fantastic births of a Wolverine or a Spider-man also carry their 'other' along, a Deadpool or The Lizard ${ }^{\text {vii }}$. There is chaos in every system, and this chaos is metaphorized in the imagined zombie figures $^{\text {viii }}$. The zombie bodies seem to be raised right from the operating tables depict a future where the bodily re-creation can become the new standard of normality and health. The alarming increase in these procedures even in the pandemic situation makes such a future not impossible to realise.

This monstrous possibility (cinematised as the birth of the zombie) can be read as having Hydra-like parallels. The mythical Hydra when destroyed only leads to the birth of two more. Significantly enough, the Red Skull also has the capacity for such a rapid 
reproduction which makes it monstrous and fearsome. In a method similar to binary fission (or asexual) way of reproduction, the increase in zombies is through bites and wounds. In the case of the surgical patients, it is by word of mouth, and so equally contagious. This is not to say that cosmetic surgeries are harmful or dangerous, because of their unsafe conditions. Rather, it is something removed from the surgical procedure itself. A progressive increase in the counts of surgeries reveals a change in the understanding of concepts of beauty, health, normality, and therefore also a change in attitude towards the notions of 'acquired' beauty. The artificiality of beauty and the plasticity of the body has placed the transformed body in an opposite pole to the 'original' body. (Whether the pre-surgical body can be called 'natural' or not is also open to discussion, but not in this paper's scope.) In the posthumanist outlook, it is difficult to label one of them as normal and the other as monstrous, and this ambivalence has made the notions more unstable.

\section{Posthumanist Promises}

The zombification process in movies is shown as a transformative process. In voodoo culture's settings in early movies, the process was intended to provide the corporeal body with a reinforced capability but a restrained will. The later narratives, situated in developed industrial and post-industrial societies, show that this process can be used to reinforce the capacities of a particularly working section of the population, like soldiers, workers and menial servants. This process makes a regular object to become more efficient, potential and useful. Similarly, medical surgeries also have evolved and gained legitimacy with the promise of more efficiency at assimilation and an alignment to aesthetic normalcy. How much of the promise is realisable and achievable is inferred from the end-result, where zombies achieve superhuman powers but those powers border on the 'monstrous.'

The surgically mutated bodies fulfil the desire to look beautiful and attractive on and off the camera. The artificial body which looks desirable on screen and in conception has its own 'other.' Where there is a perfect 'self', there is also a monstrous 'other.' The posthumanist arena of cyborg-ism promises a future where the humans can attain their superior versions. It would overpower the debilitating physiological factors like age and disease to which the fleshly human body is subjected slavishly. These imagined super-powers are attract the vulnerable human race because it feels 'powerless' in front of his own experimental creations/creatures - cyborgs, zombies, robots, humanoids (Webb \& Byrnand, 2017). A desire to be a better version of oneself underpins this posthumanist attraction for zombies, while simultaneously making their decomposing presence repulsive. Though it is true that zombies in their redefined, resurrected bodily effectivity bring closer a future, where the definition of 'super-human' can be achieved with qualities like indestructibility, invincibility and immortality. Yet, the repulsiveness for zombies arises when the promised cyborg-self - the accentuated human - does not look the way the human imagination wanted them to look. The visibility of zombies is due to their wounded and bloodied body under decay. This visibility is seen as deviating from the idealised invisibility.

Post-surgical body also is wounded and bloodied which makes them closer to the zombie figure. These bodies however beautifully and non-descriptively stitched up are resurrected bodies. They are bodies which have reborn into society and therefore no different from being zombified. But the virulence of such bodies which have undergone surgeries and come back into societal mainstream makes them the new 'natural' body. They can easily outnumber the previously 'natural' and 'normal' bodies and play out the establishment of a plastic world. Their promise is then infectious and promising, but it makes the non-operated bodies to become similar to the humans struggling for survival.

The recent zombie-centric cinematic outputs from South Korea like the Kingdom series (2019), Train to Busan (2016), \#Alive (2020) and Peninsula (2020) show the reverse side of the above posthumanist promises and try to place them in relation to reality. By 
revealing the not-cinematised percent of probability related to the birth of monstrous bodies, these projects prophesize on the change that will come in society if the harsh alternative is made manifest. They seem much like the Japanese Godzilla (1999) and the South Korean Pandora (2016) which revealed the harsher possibilities regarding scientific experiments left unattended to by Hollywood's X-men or Spider-Man series. Undesired mutations and deaths are as probable as the evolution of an altogether newer and powerful endosymbiotic organism. Scientific experimentations also have the potential to turn the familiar into a powerful and strangely fearsome entity. This makes the process as much uncanny as the object which is turned uncanny. The cinematic experiments however improbable and farfetched do reveal a parallel to the surgical procedures for cosmetic enhancement. Atkins in his essay also expressed wonder at how this torturous procedure could make some people feel better in their own estimation. His thought can very well be put in perspective by the above parallel with zombification.

\section{Conclusion: Beauty of Zombies}

Zombies have various interpretations as metaphors for victimized, resisting and/or suppressed bodies. Kyle Bishop defines zombies as 'corporeal monsters', coming out of their graves or off their death-beds right into the living society, with their distorted bodies and twisted torsos, dragging their limbs along and following things without being able to see them with their glassy eyes (Bishop, 2008). Their physicality is what makes them important metaphoric figures. The zombies, in contrast to other sick bodies, possess more glaringly visible attributes of ab-normality.

In this study, zombies have been supposed to have a consensual involvement in the zombification process. Here, we are not accounting for zombies as only the repressed bodies under a centralised control of either the shaman or a nation-state. Here, the zombies are seen as citizens in a society of control who feel they have a free-will concerning their bodies. Yet in trying to be 'model' citizens and with their 'free' wills to act, they modify their bodies only to align with the society's paradigms. There is an attempt to be more and more invisible within that society. These attempts at attaining imperceptibility are what makes the promises of medical science stranger.

The question raised was: why, after the administration of the plant essence to the sick villagers, do they turn into such figures of ugly monstrosity only, and why not into perfect physical specimens akin to a Captain America? The bedraggled look and uncontrolled bodily functioning depicted in previous zombie films like I Walked with a Zombie (1943), The Day of the Dead (1985), 28 Days Later (2003), The Walking Dead (2010, American TV series) and Rampant (2018, South Korean movie) also pose a similar question in different ways.

To establish the argument, the visually mangled bodies of zombies have been used which in the recently increasing number of zombie films have served to highlight the parallelly increasing numbers of surgical procedures to achieve a body ideal. Zombies, in their ambiguously defiant and obedient characteristics, have been used as figurative metaphors or cinematic materialisation of bodies who give in to the desire for selfmodification but do not emerge 'complete' neither in the earlier sense nor in the expected sense post-surgery.

Voodoo-based supernatural zombification could provide obedient servants in the early era of voodoo zombie movies, like Zombie Child (2019). It also brought in defiant zombies who tried to correct an injustice done to them, like Jacob's Ladder (1990). The advances of technological, biomedical and psychological tools offer a new arena for the cinematic zombie to rise - the operating theatre of cosmetic surgery. This zombie is equally virulent and more liberated in its own body. 


\section{Acknowledgements}

I would like to thank my supervisor, Dr. Meenu Gupta, Associate Professor, Panjab University (Chandigarh) for her constant support and encouragement in all my academic endeavours. I also thank my family for the unfailing love and understanding. Lastly, my deepest gratitude lies with the Department of English and Cultural Studies, Panjab University (Chandigarh) for their help with accessing reference books and reputed journals.

\section{End Notes}

i The modern audience fails because the cinematic medium allows them to see the action through to an end, without the guilt of having brought it into effect. This is discussed by Alan Cameron in his essay "Zombie media: Transmission, reproduction, and the digital dead" (published in Cinema Journal, 52(1), 2012, pp. 66-89). This distance helps when the monsters who are about to be born can also be 'killed' by switching off the device which can also be done just as and when they become too terrifying. The spatial-temporal and aesthetic distance from the action helps the audience be a part of the action but stay unincluded even then.

${ }^{\text {ii }}$ In episode 2 of Kingdom 2 (2020).

iii There are many instances from mythology and folklore about monstrous bodies which always describe them as physically incomplete, like the Ohagaru bettari, a female yokai (spirit) in Japanese folklore. She was depicted like a beautiful woman from the back but when confronted, she showed no other recognisable feature except her blackened tooth. Here the reference to blackened teeth is to the custom of teeth lacquering which was a prominent trend in Japan. (Visit http://yokai.com/ohagurobettari/) A similar fashion statement (again from Japan) was of Hikimayu (or the removal of eyebrows). A latest trend (also from Japan) is of Yaeba teeth wherein the canines are modified for a fang like appearance. These instances (all from Japan unintentionally) show how monstrosities and beauty standards have been overlapping from a long time. Instances from other societies include the killing off of twins, conjoined twins or hermaphrodite children by throwing them off at sea as found in Mesopotamian relics and in studies of some African tribal cultures.

iv Michael Jackson was often deridingly called 'Wacko Jacko' for his supposed cosmetic surgeries on his face. It was a term which always hurt him to hear (https://www.express.co.uk/entertainment/music/1342535/michael-jackson-interview-wackojacko-name-1997-dead-death-news-prince). His complete interview with Barbara Walters in the year 1997 is on YouTube (https://youtu.be/0Q1TrMzYIm8). There are often news of people getting killed because of complications related to surgeries and after multiple surgeries.

' C Dowling in her book The Cinderella complex: Women's hidden fear of independence (1982) discusses the tendency among women to feel helpless and want psychological dependence on someone (especially men). This feeling is repressed in the increasingly feminist society, where working women need to also pursue a career. S. Saha and T. Safri in their intensive study "Cinderella Complex: Theoretical Roots to Psychological Dependency Syndrome in Women" (published in International Journal of Indian Psychology, 3(3):118122, 2016) and V. Chastine and N. K. Darmasetiawan in "Cinderella Complex on Working Women" (published in Advances in Social Science, Education and Humanities Research, 308:103-106, 2019) discuss the causes, nature, contexts and extent of this 'syndrome'.

${ }^{v i}$ Captain America: The First Avenger (2011), directed by Joe Johnston. Chris Evans played the role of Captain America and Steve Rogers.

${ }^{\text {vii }}$ In the X-Men Origins: Wolverine (2009), directed by Gravin Wood. Hugh Jackman played the role of Wolverine and Logan. Ryan Reynolds played the role of Deadpool. The Amazing 
Spider-Man (2012), directed by Marc Webb. Andrew Garfield played the role of Spider-man and Peter Parker. Rhys Ifans played the role of the Lizard and Dr. Curt Connors.

viii The zombies have been qualified with the adjective 'imagined' in both the meanings of the word. They are 'imagined' in the sense of created and imaginary, and also in the sense of unreal and being placed in a negative extreme on the continuum of possibility.

\section{References}

ASPS,

(2019).

Plastic

Surgery

Statistics

Report.

https://www.eurekalert.org/pub_releases/2019-03/mnps030719.php\#: :text=According\%20to\%20the\%20ASPS\%20annual,over\%20the\% 20past\%20five\%20years

ASPS. American Society of Plastic Surgery. American Society of Plastic Surgery: https://www.plasticsurgery.org/

Atkinson, M. (2008). Exploring Male Femininity in the 'Crisis': Men and Cosmetic Surgery. Body and Society, 14(1), pp. 67-87. https://doi:10.1177/1357034X07087531

Bauman, Z. (1995). Dreams of Purity. Theoria: A Journal of Social and Political Theory (86), pp. 49-60. https://www.jstor.org/stable/41802659

Bishop, K. (2008). The Sub-Subaltern Monster: Imperialist Hegemony and the Cinematic Voodoo Zombie. The Journal of American Culture, 31(2), pp. 141-152.

Elliott, A. (2010). I Want to Look Like That!: Cosmetic Surgery and Celebrity Culture. Cultural Sociology, 5(4), pp. 463-77. https://doi:10.1177/1749975510391583

Frank, A. (2005). Body's Problems with Illness. In M. Fraser, \& M. Greco (Eds.), The Body: A Reader, pp. 318-323. Routledge.

ISAPS. (2019). ISAPS International Survey on Aesthetic/Cosmetic Procedures Performed in 2019. International Society of Aesthetic Plastic Surgery. ISAPS. https://www.isaps.org/wp-content/uploads/2020/12/Global-Survey-2019.pdf

Lee, S.-j. (Producer). (2019). Kingdom [Motion Picture]. Netflix. https://www.netflix.com/

Ozick, C. (1984). Art and Ardour. Dutton.

Webb, J., \& Byrnand, S. (2017). Some Kind of Virus: The Zombie as Body and as Trope. In

S. J. Lauro (Ed.), Zombie Theory: A Reader, pp. 111-123. University of Minnesota Press. https://www.jstor.org/stable/10.5749/j.ctt1pwt6zr.11

\section{$\underline{\text { Bio-note }}$}

Rimpa Mondal is an MPhil research scholar of English literature and Cultural studies and a UGC Fellow at Panjab University, Chandigarh, India. She has taught for some time as an Assistant Professor in English at Guru Gobind Singh College for Women (Chandigarh, India). Currently, she is overseeing postgraduate students as a teaching assistant for the paper on postcolonial literature in the Department of English and Cultural Studies, Panjab University (India). Her thrust areas are cultural studies, postcolonial literature and literary theory. The posthuman gothic in fiction and cinema is her most well-researched area.

Email: rimpamondal928@gmail.com 